\title{
A smart rotor configuration with linear quadratic control of adaptive trailing edge flaps for active load alleviation
}

\section{Bergami, Leonardo; Poulsen, Niels Kjølstad}

Published in:

Wind Energy

Link to article, DOI:

$10.1002 /$ we. 1716

Publication date:

2015

Document Version

Early version, also known as pre-print

Link back to DTU Orbit

Citation (APA):

Bergami, L., \& Poulsen, N. K. (2015). A smart rotor configuration with linear quadratic control of adaptive trailing edge flaps for active load alleviation. Wind Energy, 18(4), 625-641. https://doi.org/10.1002/we.1716

\section{General rights}

Copyright and moral rights for the publications made accessible in the public portal are retained by the authors and/or other copyright owners and it is a condition of accessing publications that users recognise and abide by the legal requirements associated with these rights.

- Users may download and print one copy of any publication from the public portal for the purpose of private study or research.

- You may not further distribute the material or use it for any profit-making activity or commercial gain

- You may freely distribute the URL identifying the publication in the public portal 


\title{
A Smart Rotor configuration with Linear Quadratic control of Adaptive Trailing Edge Flaps for active load alleviation
}

\author{
Leonardo Bergami*, Niels K. Poulsen ${ }^{\ddagger}$ \\ * DTU Wind, Technical University of Denmark, Denmark. \\ $\ddagger$ DTU Informatics, Technical University of Denmark, Denmark. \\ leob@dtu.dk
}

This is the pre-peer reviewed version of the following article: Bergami, Leonardo, and Niels K. Poulsen. A Smart Rotor configuration with Linear Quadratic control of Adaptive Trailing Edge Flaps for active load alleviation. Wind Energy, February 2014, Early View. doi:10.1002/we.1716, which has been published in final form at Wiley Online Library

\begin{abstract}
The paper proposes a smart rotor configuration where Adaptive Trailing Edge Flaps (ATEF) are employed for active alleviations of the aerodynamic loads on the blades of the NREL $5 \mathrm{MW}$ reference turbine. The flaps extend for $20 \%$ of the blade length, and are controlled by a Linear Quadratic (LQ) algorithm based on measurements of the blade root flapwise bending moment. The control algorithm includes frequency weighting to discourage flap activity at frequencies higher than $0.5 \mathrm{~Hz}$. The linear model required by the LQ algorithm is obtained from subspace system identification; periodic disturbance signals described by simple functions of the blade azimuthal position are included in the identification to avoid biases from the periodic load variations observed on a rotating blade. The LQ controller uses the same periodic disturbance signals to handle anticipation of the loads periodic component.

The effects of active flap control are assessed with aeroelastic simulations of the turbine in normal operation conditions, as prescribed by the IEC standard. The turbine lifetime fatigue damage equivalent loads provide a convenient summary of the results achieved with ATEF control: a $10 \%$ reduction of the blade root flapwise bending moment is reported in the simplest control configuration, whereas reductions of approximately $14 \%$ are achieved by including periodic loads anticipation. The simulations also highlight impacts on the fatigue damage loads in other parts of the structure, in particular, an increase of the blade torsion moment, and a reduction of the tower fore-aft loads.
\end{abstract}

\section{Introduction}

The continuously increasing size of modern utility-scaled wind turbines calls for technical solutions able to reduce the loads the turbine has to withstand, thus allowing for lower structural requirements, and savings in rotor weight and 
material usage. Several investigations have highlighted the potential of smart rotor concepts [1]: wind turbine rotors that, through a combination of sensors, control units, and actuators, actively alleviate the aerodynamic loads the rotor is subject to.

Smart-rotors can employ traditional blade pitch actuators $[2,3]$, or active aerodynamic devices, which can modify the aerodynamic forces locally along the blade span. Active devices as Adaptive Trailing Edge Flaps (ATEF) with a continuous deflection shape have favorable aerodynamic characteristics [4]; their potential was first assessed on $2 \mathrm{D}$ airfoil sections, with simulations $[5,6]$, and wind tunnel experiments on non-rotating rigs $[7,8]$. The application of Adaptive Trailing Edge Flaps to alleviate loads on wind turbines rotors was then investigated by means of aeroelastic simulations, and also by two rotating experiments: the DUWIND group at Delft university tested a two bladed smartrotor in an open jet wind tunnel [9, 10], and Castaignet et al. [11] carried out a full scale experiment on a $225 \mathrm{~kW}$ turbine with flaps on one of the three blades.

All the investigations confirmed that smart rotors with trailing edge flaps have a potential for reducing the fatigue loads experienced by the turbine; nevertheless, they reported rather widespread results, with load reductions figures ranging from 5 to 47 percent, see the summary compiled by Barlas et al. [12]. Differences in the alleviation performances can originate from several sources: the models used in the aeroelastic simulations, the conditions of the wind field and its turbulence levels, the maximum deflection and extension of the flap actuators, and also the choices made in designing the flap control system, as the assumptions on the available sensors and measurements, and the type of control algorithm implemented.

Most of the studies opted for control algorithms based on classic PID methods, applied either to each blade independently $[13,14,15,16,17]$, or to the whole rotor through multi-blade coordinate transformation [18, 19]; other investigations have instead applied model based control algorithms, as Linear Quadratic Regulators (LQR) [20], Model Predictive Control (MPC) [12, 21], or $H_{\infty}$ control [9]. The flap control actions respond to the deformation state of the rotor blades; in some cases, rotor sensors are assumed to provide direct measurements of the blade deflection and deflection rate $[15,20,22,17]$, whereas other controllers use measurements of the blade flapwise bending moment, either at selected locations along the span $[14,16]$, or, more simply, at the blade root $[19,12,21,10]$. Some studies have also investigated flap control algorithms where additional information on the in-flow condition along the blade are provided, for instance, by measurements performed with Pitot's tubes mounted on the blade leading edge $[14,12,21]$.

The present work considers a setup where the flaps on each of the blades are controlled based on measurements of the flapwise bending moment at the root of the same blade. The setup has the advantage of relying on a simple sensor arrangement, relatively easy to implement and maintain. Furthermore, the controller aim is to alleviate fatigue loads at the blade root, taking measurements at the same location guarantees that the control unit processes measurement signals describing the same loads it has to alleviate. Measuring the flapwise bending moment at the blade root though poses some challenges to the control algorithm, as the effects of the flap deflection on the root moment are observed with a delay, and display non-minimum phase behavior: the variation in the measured signals has an initial transient of sign opposite to the load variation 
reached at the end of the transient. A model based Linear Quadratic (LQ) regulator is chosen to better cope with the large delay and the non-minimum phase response.

The LQ control algorithm, described in section 3.2, adopts a state-space formulation, where the states are estimated from the blade root flapwise bending moment measurements with a Kalman observer [23]. Each blade is treated as an independent Single Input Single Output (SISO) system, and the control and the Kalman observer models are obtained by subspace system identification [24]. Frequency weighting of the control action is introduced to reduce the flap activity at high frequency, and thus limit actuator wear. The classic LQ formulation is modified to handle periodic disturbance rejection [25]. An important contribution to the load variation on a wind turbine blade has in fact a deterministic periodic nature [26, 27]: constant or slow varying sources of disturbances (as gravity, tower shadow, tilt, wind shear, yaw misalignment) produce on the rotating blade load variations with marked periodic components, which depend on the blade azimuthal position and occur at every rotor revolution. Knowledge of the periodic, and hence predictable, disturbances is exploited in the control algorithm, which anticipates, and try to compensate for, the load variations caused by the periodic components. The periodic disturbances are described by simple functions of the blade azimuthal position, and disturbance anticipation does not require additional measurements other than the blade azimuthal position, which again can be obtained with relatively simple and low-maintenance sensors.

The investigation on the flap potential is carried out by means of aeroelastic simulations performed with the code HAWC2 [28], which couples a multi-body structural model with a Blade Element Momentum (BEM) aerodynamic model including steady and dynamic effects of the flap deflection [29]. The load alleviation potential is evaluated for wind conditions prescribed by the IEC standard [30], with turbulence intensity for a class B turbine and a 3D turbulent field generated according to Mann's model [31]; the flap performances are evaluated at mean wind speed above rated, ranging from 12 to $24 \mathrm{~m} / \mathrm{s}$. The following section describes the simulation environment, the flap actuator setup, and briefly introduces the models used by the aeroelastic code HAWC2. The LQ control algorithm is presented in section 3, and section 4 reports the results of the aeroservoelastic simulations and quantifies the load alleviation potential achieved by the active flap control.

\section{Simulation environment}

\subsection{Aeroelastic code HAWC2}

All the simulations in the study are carried out using the aeroelastic code HAWC2 [28], which features a structural model based on a multi-body finite element formulation. The wind turbine structure is represented by a number of bodies, each of them modeled as a sequence of Timoshenko beam elements, which include beam shear and torsion properties. The torsion degree of freedom, of particular importance given the significant aerodynamic torsional moment generated by the flaps, is thus innately included in the structural model. The turbine blades are then represented by a series of bodies, thus accounting for 
the non-linear and coupling effects introduced by large blade deflections.

The aerodynamic part of the code follows a Blade Element Momentum (BEM) formulation: a $2 \mathrm{D}$ model is used to compute the integral aerodynamic forces and pitching moments on each blade section, and is coupled with a rotor induction model that includes Glauert and Prandtl corrections, as well as a dynamic inflow model [32]. The ATEFlap model [29] is used to describe the dynamics of lift, drag, and moment on 2D blade sections with flaps, and consists essentially of a potential flow solution [33] coupled with a Beddoes-Leishmann type of dynamic stall model [34]; the potential flow solution is based on a superposition of Wagner-type indicial response functions, here the classic flat plate response function is slightly modified to account for the thickness of the airfoil [35].

\subsection{Reference wind turbine and flap setup}

The study considers a smart rotor setup where adaptive trailing edge flaps are applied to the NREL 5-MW reference wind turbine [36], which has a rotor of 126 $\mathrm{m}$ diameter and a 3 bladed up-wind configuration typical of modern multi-MW turbines, table 1 . The turbine baseline controller operates the rotor at variable speed below rated conditions, and limits the power above rated by collectively pitching the blades to feather based on low-pass filtered measurements of the shaft speed [36]. The baseline controller is left unchanged, and the active flap load control is simply superimposed; in the investigated cases, the mutual interference between the flap load control and the pitch power limitation was found to be very small.

The load alleviation achieved with active flap control greatly depends on the extension and type of flap actuators. The adaptive trailing edge flaps in this investigation, table 1 , extend for $10 \%$ of the airfoil chord, and introduce a smooth deflection shape in the airfoil camber-line that outlines a circular arc [29]. The flaps are applied to the NACA 64 airfoil of $17 \%$ thickness found in the outboard part of the turbine blades; the flap deflection is limited to $\pm 10^{\circ}$, and the corresponding variations of the steady aerodynamic coefficients for the airfoil section are computed with Computational Fluid Dynamics [29], figure 1. The maximum steady lift coefficient variation ranges from -0.45 to +0.41 , which indicatively corresponds to the lift coefficient variation obtained with angle of attack changes from $-3.9^{\circ}$ to $+3.6^{\circ}$; due to the smooth deformation shape only a minor drag penalty is reported at small angles of attack, figure 1(b).

The flaps cover $20 \%$ of the blade spanwise length, from $47.7 \mathrm{~m}$ to $60.0 \mathrm{~m}$ of the blade span; when deflected to their $+10^{\circ}$ limit they cause a variation in the blade root flapwise bending moment $(\Delta \mathrm{Mx}$.Bl.Rt) of approximately 1100 $\mathrm{kNm}$ (fig.3), which is roughly equivalent to the variation achieved by $1^{\circ}$ change of the whole blade pitch angle. In this study, flap sections located on the same blade are all deflected according to the same control signal, which is based on measurements of the blade azimuthal position, and the flapwise bending moment at the root of the same blade.

\subsection{Wind conditions}

The aim of the aeroelastic simulations is to evaluate the load alleviation potential achieved with the adaptive flaps in realistic operation conditions. The simula- 


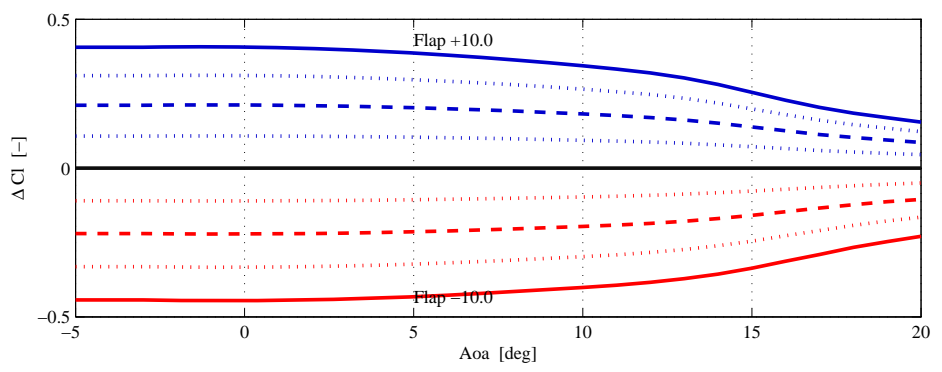

(a) Lift Coefficient

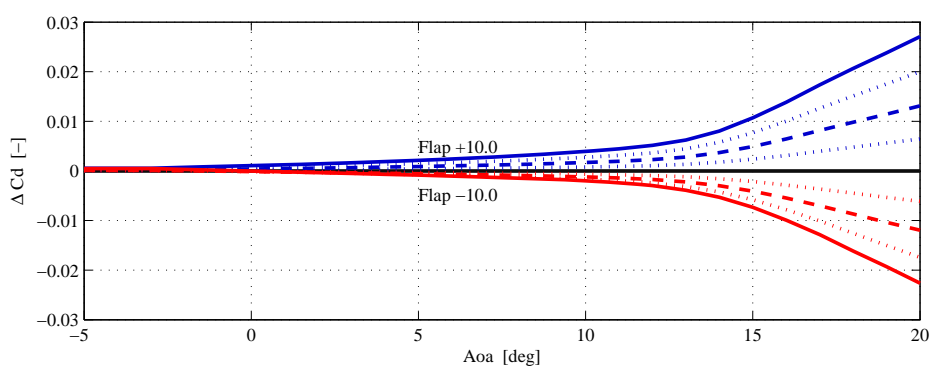

(b) Drag Coefficient

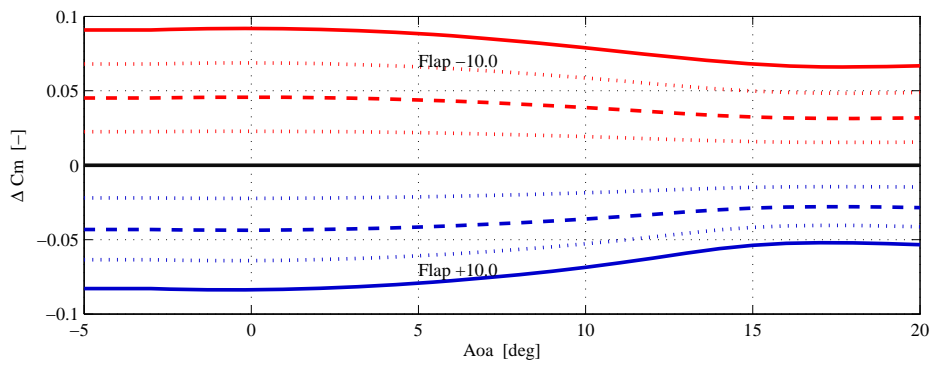

(c) Moment Coefficient

Figure 1: Airfoil section steady aerodynamic coefficient variations achieved by the investigated Adaptive Trailing Edge Flaps. Blue lines indicate positive (downward) flap deflections, red lines negative (upwards) deflections; full lines corresponds to the maximum deflections of $\pm 10^{\circ}$, dashed lines to $\pm 5^{\circ}$, and the dotted lines to $\pm 2.5^{\circ}$ and $\pm 7.5^{\circ}$.

\begin{tabular}{|cc|rc|}
\hline \multicolumn{2}{|c|}{ Reference Wind Turbine } & \multicolumn{2}{c|}{ Flap Setup } \\
\hline Rat. Power & $5 \mathrm{MW}$ & Chordwise ext. & $10 \%$ \\
Num.Blades & 3 & Deflect.limits & $\pm 10^{\circ}$ \\
Rotor Diam. & $126 \mathrm{~m}$ & Max. $\Delta \mathrm{Cl}$ & $-0.45 \sim+0.41$ \\
Blade length & $61.5 \mathrm{~m}$ & Spanwise length & $12.3 \mathrm{~m}(20 \%$ blade length $)$ \\
Rat. Rot.Sp. & $1.267 \mathrm{rad} / \mathrm{s}$ & Spanwise loc. & from $47.7 \mathrm{~m}$ to $60.0 \mathrm{~m}$ span \\
Hub height & $90 \mathrm{~m}$ & Max. $\Delta$ Mx.Bl.Rt & approx. $\pm 1100 \mathrm{kNm}$ \\
\hline
\end{tabular}

Table 1: Main characteristics of the NREL reference wind turbine [36], and the adaptive trailing edge flaps setup considered in the investigation. 
tions are thus carried out in wind conditions prescribed by the IEC standard design load case 1.1 [30], which corresponds to normal wind turbine operation. The wind field is characterized by a normal terrain shear, described by the power law relation with exponent 0.2 ; the effects of tower shadow are accounted for, and Mann's turbulence model [31] is applied to generate a 3D turbulent field for a class B turbine, with turbulence intensity ranging from $17 \%$ at $12 \mathrm{~m} / \mathrm{s}$ to $14 \%$ at $24 \mathrm{~m} / \mathrm{s}$.

Bergami and Gaunaa [27] report that wind turbine operations below rated wind speed are responsible for only minor contribution to the blade flapwise lifetime fatigue damage; furthermore, active alleviation of the rotor loads below rated power would reduce the turbine energy capture. Therefore, in this case, the flap load alleviation control is only applied to operation above rated wind speed, and aeroelastic simulations are performed for mean wind speeds from 12 to $24 \mathrm{~m} / \mathrm{s}$. A total of $1 \mathrm{hr}$ turbulent wind field is simulated at each mean wind speed (6 seeds of 10 minutes), and identical turbulent fields are used to compare the different control configurations. The mean wind speed distribution, used to evaluate lifetime equivalent loads on the turbine structure, follows a Rayleigh probability density function, with average wind speed of $8.5 \mathrm{~m} / \mathrm{s}$ (class II turbine in the IEC standard [30]).

\section{Control design}

The active flap control presented here relies on a model based control algorithm that requires a linear time invariant model of the system to be controlled. The control model should be as simple as possible, and, at the same time, sufficiently complex to capture the relevant dynamics of the system, and to outline, with an accuracy adequate to the control scope, the relation between the measured output $y$, the control input $u$, and the disturbances acting on the system. In this case, the measured output $y$ consists of the blade root flapwise bending moment (Mx.Bl.Rt), the control signal $u$ determines the flap deflection angle, and the disturbances are split into a stochastic component $e$, and a periodic (measurable) component $d$. The control model is described by a state-space system in discrete time, where the system states at time step $i$ are collected by the vector $x_{i}$. The discrete time state-space system is cast in innovation form [23], thus reading:

$$
\left\{\begin{array}{l}
x_{i+1}=\boldsymbol{A} x_{i}+\boldsymbol{B} u_{i}+\boldsymbol{G} d_{i}+\boldsymbol{K} e_{i} \\
y_{i}=\boldsymbol{C} x_{i}+e_{i}
\end{array}\right.
$$

Each of the three rotor blades, with its flap actuators and bending moment sensor, is described by a separate Single Input Single Output (SISO) system, eq. (1), which is assumed independent from the others; although based on a rather crude assumption, the approximation is a convenient practice to simplify the blade load control problem.

\subsection{System Identification}

A model for the system to control could be retrieved from the same first principle models that are used in the aeroelastic simulation code. Such models though would return a rather complex description, characterized by non-linearities and a 
large number of states, and would require further processing in order to obtain a model suitable for our control purposes. Instead, a model of the system dynamics of interest is obtained by applying system identification techniques to 'measurements' of the system response, which are collected from simulations performed with the aeroelastic code HAWC2.

System identification on a rotating blade is complicated by the strong influence of periodic disturbances, which violate the assumption of measurements noise of stochastic nature. The periodic component would produce a bias in the identified system, as the identification process would try to explain the periodic variations observed in the measurements by altering the system dynamics. Van der Veen et al. [37] propose an elegant solution by including in the identification process additional input signals, which are generated by periodic signals with the same period as the blade rotation.

The additional periodic input signals are formulated as an external periodic disturbance term, $d$ in eq. (1); the periodic disturbance signals are simple functions that only depend on the blade azimuthal position, and are hence easy to measure, and predict. Two types of periodic disturbance signals are considered in the study:

- $d$ Sin-Cos: following the classic approach [37, 9, 10], a two components signal is built by taking the sine and the cosine of the blade azimuthal position, blue lines in the top plot of figure 4 .

- $d$ Wsp: a single component periodic signal is retrieved from a simple model of the free wind speed variations observed in the blade rotating frame. The wind speed variation only account for terrain shear and tower shadow effects, the latter causing the marked indentation of the signal around $0^{\circ}$ azimuth, red line in the top plot of figure 4 .

The identification is performed on set of 'measurements' of the blade root flapwise bending moment that are retrieved from aeroelastic simulations of the turbine in normal operation while the flap actuators excite the blade following a Pseudo Random Binary Signal (PRBS) that spans the maximum available deflection range of $\pm 10^{\circ}$. The identification is carried out with the subspace method described by Ljung [24], which supports the narrow-banded additional input signals given by the periodic disturbance terms, and returns a system description in state-space innovation form, eq. (1), hence providing a direct estimation of the Kalman gain matrix $\boldsymbol{K}$, eq. (13).

A linear system description with four states was found adequate for the control purposes of this study. The frequency response from flap deflection to blade root flapwise bending moment of the identified four state linear model (blue line in the Bode plots of fig. 2) is compared to the response outlined with spectral estimation (black full line), and to the frequency response obtained from a series of aeroelastic simulations where the flap deflection follows a single-frequency sinusoidal signal and all the sources of periodic disturbances have been ideally removed from the simulation (gray circles in fig. 2). The identified model describes fairly well the response for frequencies up to the second blade flapwise mode (at approximately $1.7 \mathrm{~Hz}$ ), with a small discrepancy in the low frequency range. Both the simulated response and the spectral estimation show a small indentation slightly above $0.3 \mathrm{~Hz}$, not captured by the identified model; the indentation corresponds to the first natural frequency of the tower, which absorbs 
part of the energy from the flap actuation. The presence of tower dynamics in the blade response to the flap deflection indicates that the assumption of each blade being independent from the rest of the structure is not entirely correct; nevertheless, its effects are only of secondary importance for the control aim of the study. The Bode plots also report the frequency response obtained with a spectral estimate where the additional periodic disturbance inputs are not taken into account (dashed line Spa npt in fig. 2); the estimate in this case would display a clear bias close to the $1 \mathrm{P}$ rotational frequency of $0.2 \mathrm{~Hz}$. The effects of neglecting the blade torsional degree of freedom are assessed by simulating the frequency response from flap action with a turbine model where the blades are stiff in torsion (gray line with diamonds in fig. 2); the results indicate an overestimation of the response magnitude ranging between 2 and $3.5 \mathrm{~dB}$. A correct representation of the blade torsion degree of freedom is hence important in aeroelastic simulation evaluating the effects of active flap control, as neglecting it would yield to an overestimation of the flap effects, which, in this particular case, ranges between 20 and $45 \%$.
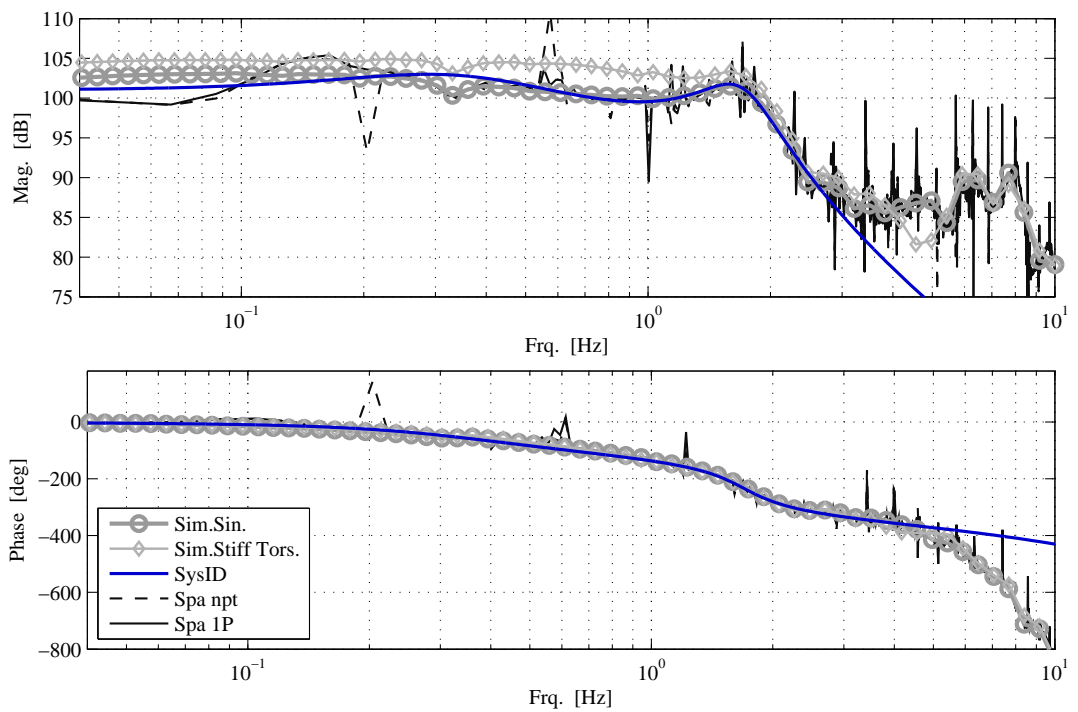

Figure 2: Bode plot, frequency response from flap action to blade root flapwise bending moment Mx.Bl.Rt. The response from the identified system (blue line) is compared to a spectral estimate (full black line), and to the response from a series of sinusoidal flap action simulations in ideal conditions (gray circles). The response for spectral estimate without periodic term correction (dashed black line), and for simulations with blades stiff in torsion (gray diamonds) are given for comparison.

The identified models are verified in the time domain by comparing the response to a step flap deflection against the step response simulated with HAWC2, figure 3; again, ideal conditions are enforced in the HAWC2 simulations by removing the sources of periodic disturbances (gravity, wind shear, tower shadow, rotor misalignment). The identified linear model reproduces the main characteristics of the simulated step response: the non-minimum phase transient, the raising time, and the total variation achieved in the root flapwise bending moment. The simulated response presents a low frequency oscillation that is not captured by the identified model, and probably corresponds to the 
offset observed in the low frequency range of the Bode plots.
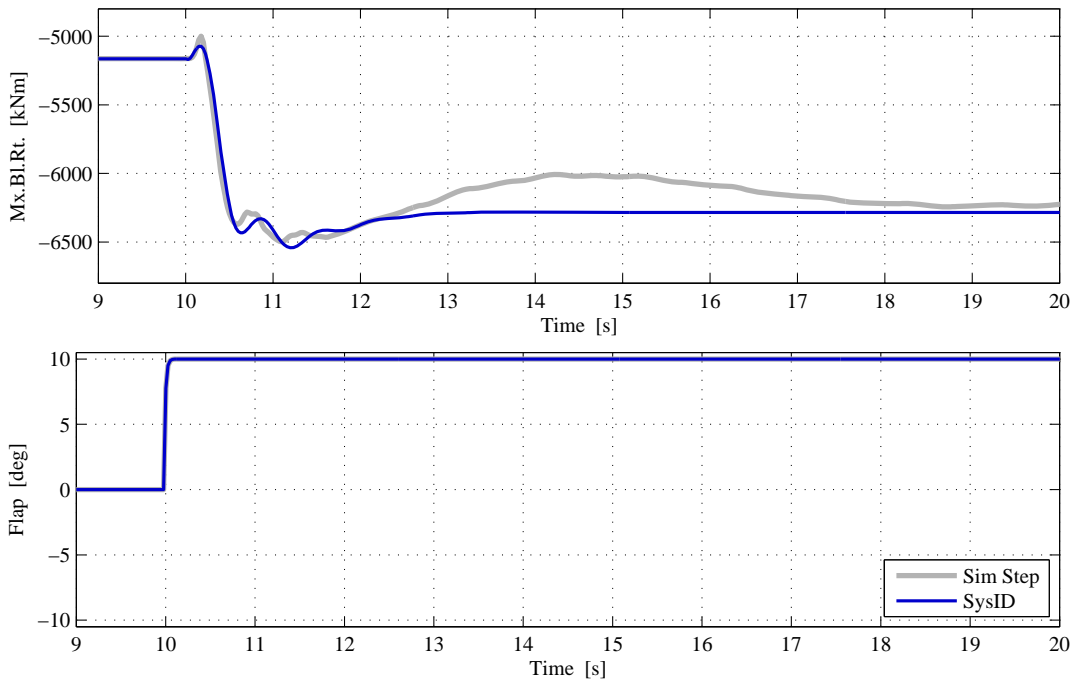

Figure 3: Step response to a positive flap deflection: the increase in lift further deflects the blade to leeward (negative flapwise bending moment). Comparison of the response predicted by the identified system (blue line), and the response from aeroelastic simulations with removed periodic effects (gray line).

The identified systems also describe the influence that periodic disturbances have on the blade flapwise moment. The bending moment variations predicted by the identified linear systems in response to the periodic disturbance signals $d$ Sin-Cos and $d$ Wsp are compared against the bending moment variation observed in HAWC2 simulations of the turbine operating in a non-turbulent wind field, lower plot in figure 4. Both identified models capture the bending moment variation related to terrain shear effects, and correctly estimate the amplitude and phase of the load variation. The linear system with the $d W s p$ disturbance signal also captures the effects of the tower passage, and correctly reproduces the phase lag observed in the sytem dynamics, as the the blade flapwise bending moment variation is felt with a phase delay of approximately $20^{\circ}$ after the tower passage. Note that the flapwise bending moment variation from periodic components (approx. $\pm 2000 \mathrm{kNm}$ ) is already larger than the variation achieved by the flap actuators (approx. $\pm 1100 \mathrm{kNm}$ ). The flaps will thus often operate close to their deflection limits; future work might investigate whether a model predictive control algorithm, which takes into account the flap deflection constraints, would deliver better load alleviation performances than the chosen Linear Quadratic controller.

Finally, the identified linear model is tested by reproducing the response to gaussian random activity of the flap actuator on the rotating blades, and comparing the time series against the one simulated with the complete aeroelastic turbine model in $\mathrm{HAWC}$, figure 5. With low wind turbulence intensity $(2 \%)$, the identified model is able to reproduce the simulated output with a good approximation. The agreement between the linear models predictions and the aeroelastic simulation results is quantified in terms of variance-accounted-for (VAF) $[37,10]$. The linear model with the $d$ Sin-Cos periodic disturbance signal 

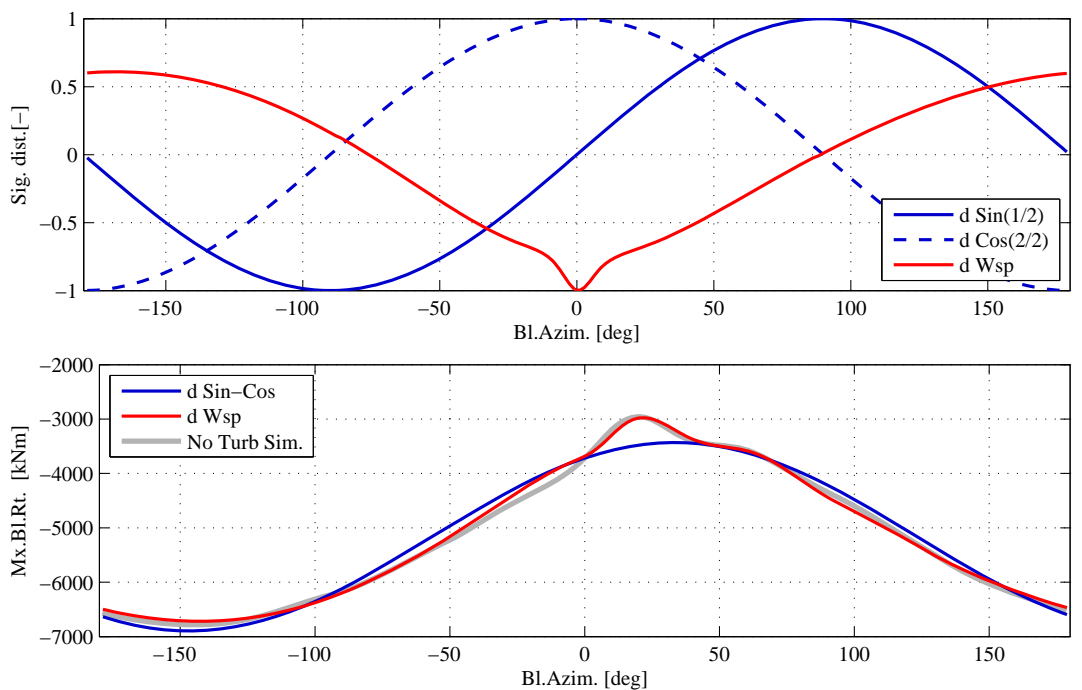

Figure 4: Periodic disturbance signals (top), and periodic component of the blade root flapwise bending moment variation versus blade azimuthal position at $16 \mathrm{~m} / \mathrm{s}$ (bottom); the blade pointing downwards in front of the tower has $0^{\circ}$ azimuth, positive direction for clockwise rotations when looking downwind.

accounts for $94.3 \%$ of the variance observed in the simulated output; whereas, the model with the $d W s p$ disturbance signal reaches higher VAF (95.4\%), and better captures the sharp bending moment variations caused by the blade tower passage.

The dynamics of the bending moment response from flap deflection maintain similar characteristics at different operating wind speed, as long as the rotor speed keeps close to its rated value. On the contrary, the system response to the periodic disturbance signals depends on the wind speed, as the amplitude of the periodic load variation increases with the mean wind speed. In this investigation, the problem is tackled by simply retrieving a linear model description for each of the operating mean wind speed that will be considered in the load alleviation simulations. Future works might consider solutions more suitable to 'real-life' applications, as control algorithms including linear parameter variation or online system identification.

\subsection{Linear Quadratic regulator with disturbance rejection}

Given the dynamic system described by the discrete time affine linear time invariant model in eq. (1), the objective of the Linear Quadratic regulator is to return a control signal $u$ that minimizes the cost function

$$
J=\sum_{i=0}^{N} z_{i}^{T} \boldsymbol{W} z_{i}
$$



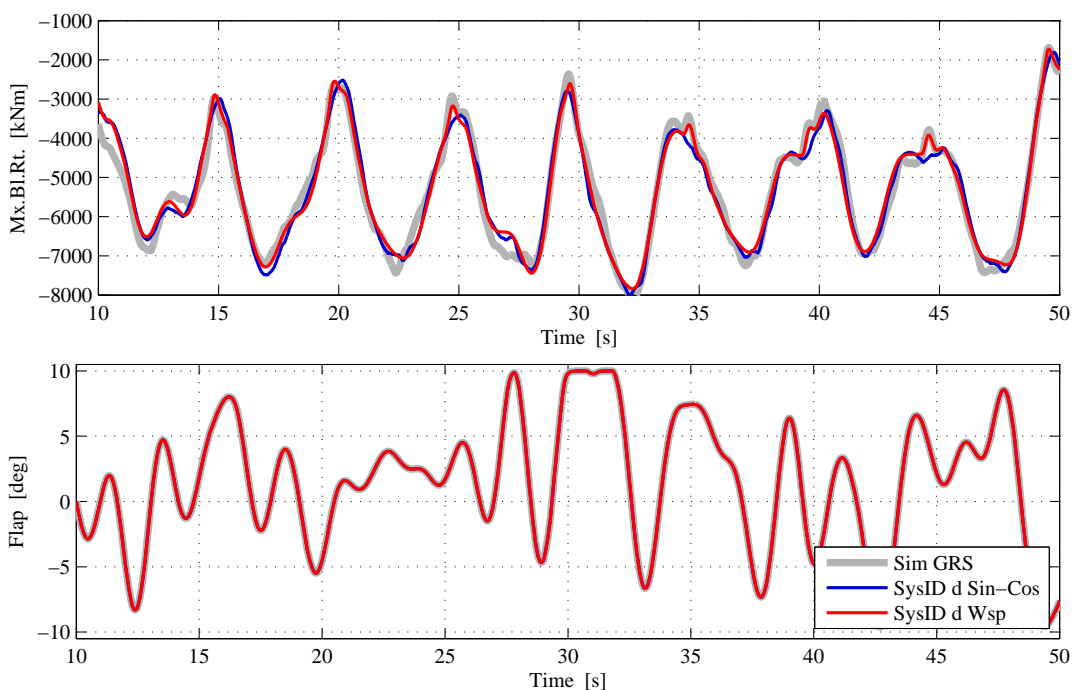

Figure 5: System identification validation time series, blade root flapwise bending moment response to deflection of flap following a GRS series. Comparison of the response predicted from the identified linear models with aeroelastic simulation.

where the augmented error vector $z$ includes both the controlled output $y$ and the control action $u$ :

$$
z_{i}=\left[\begin{array}{c}
\hat{y}_{i} \\
u_{i}
\end{array}\right]=\left[\begin{array}{l}
\boldsymbol{C} \\
\mathbf{0}
\end{array}\right] x_{i}+\left[\begin{array}{l}
\mathbf{0} \\
\boldsymbol{I}
\end{array}\right] u_{i}=\boldsymbol{C}_{\boldsymbol{z}} x_{i}+\boldsymbol{D}_{\boldsymbol{z}} u_{i}
$$

The objective of the controller is thus to limit the variation of the output signal $y$, and, at the same time, limit the control action $u$. The weight on the control action is adjusted by the tuning parameter $\rho_{u}$, which is included in the cost function weight matrix $\boldsymbol{W}$ :

$$
\boldsymbol{W}=\left[\begin{array}{cc}
1 & 0 \\
0 & \rho_{u}^{2}
\end{array}\right]
$$

The cost function can be rewritten as

$$
\begin{aligned}
& J=\sum_{i=0}^{N}\left[\begin{array}{ll}
x_{i}^{T} & u_{i}^{T}
\end{array}\right]\left[\begin{array}{cc}
\boldsymbol{Q} & \mathbb{N} \\
\mathbb{N}^{T} & \boldsymbol{R}
\end{array}\right]\left[\begin{array}{l}
x_{i} \\
u_{i}
\end{array}\right], \quad \text { where } \\
& \boldsymbol{Q}=\boldsymbol{C}_{\boldsymbol{z}}{ }^{T} \boldsymbol{W} \boldsymbol{C}_{\boldsymbol{z}}, \quad \boldsymbol{R}=\boldsymbol{D}_{\boldsymbol{z}}{ }^{T} \boldsymbol{W} \boldsymbol{D}_{\boldsymbol{z}}, \quad \mathbb{N}=\boldsymbol{C}_{\boldsymbol{z}}{ }^{T} \boldsymbol{W} \boldsymbol{D}_{\boldsymbol{z}}
\end{aligned}
$$

which is the standard formulation of a Linear Quadratic (LQ) problem with cross coupling terms.

The LQ problem is solved taking into account the disturbance signal $d$, here given by simple functions of the blade azimuthal position (see fig. 4). The periodic disturbance signals $d$ thus serve a double scope: first they avoid biases from periodic variations during the system identification step; then, the relation between the same signals and the output is exploited by the LQ controller, which is thus able to anticipate future load variations caused by the periodic disturbance components. 
Lewis et al.[25] indicate a stationary solution (for $N \rightarrow \infty$ ) to the LQ problem, where the control signal $u_{i}$ is given by a sum of a feedback on the system states $x_{i}$, on the current disturbance $d_{i}$, and on a signal $v_{i+1}$ that includes future disturbances:

$$
u_{i}=-\left(\boldsymbol{L} x_{i}+\boldsymbol{U} v_{i+1}+\boldsymbol{M} \boldsymbol{G} d_{i}\right), \quad \text { where: }
$$

$\boldsymbol{L}=\left(\boldsymbol{R}+\boldsymbol{B}^{T} \boldsymbol{S} \boldsymbol{B}\right)^{-1}\left(\boldsymbol{B}^{T} \boldsymbol{S} \boldsymbol{A}+\mathbb{N}^{T}\right), \boldsymbol{U}=\left(\boldsymbol{R}+\boldsymbol{B}^{T} \boldsymbol{S} \boldsymbol{B}\right)^{-1} \boldsymbol{B}^{T}, \boldsymbol{M}=\left(\boldsymbol{R}+\boldsymbol{B}^{T} \boldsymbol{S} \boldsymbol{B}\right)^{-1} \boldsymbol{B}^{T} \boldsymbol{S}$

a closed-loop description of the system is thus available. The matrix $\boldsymbol{S}$ in the control action terms is the solution to the algebraic Riccati equation:

$$
\boldsymbol{S}=\boldsymbol{A}^{T} \boldsymbol{S} \boldsymbol{A}+\boldsymbol{Q}-\left(\boldsymbol{A}^{T} \boldsymbol{S} \boldsymbol{B}+\mathbb{N}\right)\left(\boldsymbol{R}+\boldsymbol{B}^{T} \boldsymbol{S} \boldsymbol{B}\right)^{-1}\left(\boldsymbol{B}^{T} \boldsymbol{S} \boldsymbol{A}+\mathbb{N}^{T}\right) .
$$

The signal $v_{i}$ is given by the adjoint of the closed loop system with a backwards recursion on the (predicted) future disturbance signals:

$$
v_{i}=(\boldsymbol{A}-\boldsymbol{B} \boldsymbol{L})^{T}\left(v_{i+1}+\boldsymbol{S} \boldsymbol{G} d_{i}\right),
$$

with terminal condition $v_{N}=0$, where, in practice, $N$ is a finite number sufficiently large as to avoid any transient effect.

\subsubsection{Frequency weighting}

Frequency weighting is introduced in the LQ cost function, eq. (2), in order to penalize output variations or flap actions in certain frequency ranges. The error signal $z$ is given by filtered versions of the output $y^{f}$ and the control action $u^{f}$, which are obtained through linear state-space descriptions chosen as to increase the response gain in the frequency range to penalize:

$$
u:\left\{\begin{array}{ll}
x_{i+1}^{u} & =\boldsymbol{A}^{\boldsymbol{u}} x_{i}^{u}+\boldsymbol{B}^{\boldsymbol{u}} u_{i} \\
u_{i}^{f} & =\boldsymbol{C}^{\boldsymbol{u}} x_{i}^{u}+\boldsymbol{D}^{\boldsymbol{u}} u_{i}
\end{array} \quad \text { and } \quad \hat{y}:\left\{\begin{array}{l}
x_{i+1}^{y}=\boldsymbol{A}^{\boldsymbol{y}} x_{i}^{y}+\boldsymbol{B}^{\boldsymbol{y}} \hat{y} \\
y_{i}^{f}
\end{array}\right.\right.
$$

The state vector of the system is extended $x^{\text {ext }}$ to include the filter states $x^{u}$ and $x^{y}$, the extended error signal $z$ is computed as

$$
z_{i}=\left[\begin{array}{c}
y_{i}^{f} \\
u_{i}^{f}
\end{array}\right]=\left[\begin{array}{ccc}
\boldsymbol{D}^{y} \boldsymbol{C} & \boldsymbol{C}^{\boldsymbol{y}} & \mathbf{0} \\
\mathbf{0} & \mathbf{0} & \boldsymbol{C}^{\boldsymbol{u}}
\end{array}\right]\left[\begin{array}{c}
x_{i} \\
x_{i}^{y} \\
x_{i}^{u}
\end{array}\right]+\left[\begin{array}{c}
\mathbf{0} \\
\boldsymbol{D}^{\boldsymbol{u}}
\end{array}\right] u_{i}=\boldsymbol{C}_{\boldsymbol{z}}^{\mathrm{ext}} x_{i}^{\mathrm{ext}}+\boldsymbol{D}_{\boldsymbol{z}}^{\mathrm{ext}} u_{i}
$$

and the state equation, eq. (1), is reformulated in terms of extended state vectors and extended matrices:

$x_{i+1}^{\mathrm{ext}}=\left[\begin{array}{l}x_{i+1} \\ x_{i+1}^{y} \\ x_{i+1}^{u}\end{array}\right]=\left[\begin{array}{ccc}\boldsymbol{A} & \mathbf{0} & \mathbf{0} \\ \boldsymbol{B}^{\boldsymbol{y}} \boldsymbol{C} & \boldsymbol{A}^{\boldsymbol{y}} & \mathbf{0} \\ \mathbf{0} & \mathbf{0} & \boldsymbol{A}^{u}\end{array}\right]\left[\begin{array}{c}x_{i} \\ x_{i}^{y} \\ x_{i}^{u}\end{array}\right]+\left[\begin{array}{c}\boldsymbol{B} \\ \mathbf{0} \\ \boldsymbol{B}^{\boldsymbol{u}}\end{array}\right] u_{i}+\left[\begin{array}{c}\boldsymbol{G} \\ \mathbf{0} \\ \mathbf{0}\end{array}\right] d_{i}=\boldsymbol{A}^{\mathrm{ext}} x_{i}^{\mathrm{ext}}+\boldsymbol{B}^{\mathrm{ext}} u_{i}+\boldsymbol{G}^{\mathrm{ext}} d_{i}$. 
The frequency weighting is included in the controller by using the extended matrices in the equations for the cost function matrices eq. (5), the algebraic Riccati equation (8), and the LQ gain matrices eq. (7).

In this investigation, frequency weighting is only applied to the control signal $u$, and penalizes control actions with frequencies above $0.5 \mathrm{~Hz}$. The frequency weighting reduces flap activity and flap deflection speed, thus potentially increasing the life-time of the flap actuators; the effects on the fatigue load alleviation reduction are minor, as the largest contribution to the blade fatigue damage originates at lower frequencies [19, 27].

\subsubsection{State estimation}

The control action is based on a feedback from the system states $x$. The states though, are not measured directly, in their place the control uses estimated states $\hat{x}$, which are retrieved with a Kalman filter estimator [23] from measurements of the blade root flapwise bending moment $y_{i}$ :

$$
\hat{x}_{i+1}=\boldsymbol{A} \hat{x}_{i}+\boldsymbol{B} u_{i}+\boldsymbol{G} d_{i}+\boldsymbol{K}\left(y_{i}-\boldsymbol{C} \hat{x}_{i}\right) .
$$

The linear model descriptions used by the Kalman filter estimator, as well as the Kalman gain matrix $\boldsymbol{K}$, are also retrieved from the innovation state-space description returned by the subspace system identification, eq. (1), thus avoiding the need of further tuning the Kalman observer.

\section{Aeroelastic simulation results}

The LQ regulator is implemented in the simulation tool, and the blade load alleviation performances of the smart rotor set-up are assessed with a series of aeroelastic simulations during normal production, above rated wind speed, and with the turbulent wind field prescribed by the IEC standard [30] for a class B turbine.

Three flap control configurations are investigated, and the resulting loads are compared to the reference case of no active flap control. In the first control configuration (denoted as $d 00$ ), the LQ regulator has no information about the periodic disturbances: it does not anticipate the periodic load variation, and it only acts based on the measurement feedback. The $d$ Sin-Cos configuration handles periodic disturbance anticipation based on the harmonic sine and cosine disturbance signals; the $d W s p$ configuration anticipates instead the periodic load variation based on the disturbance signal of the simplified free wind speed variation. All the control configurations are tuned by acting on the control weight, $\rho_{u}$ in eq. (4), so to reach a compromise between blade flapwise fatigue damage alleviation, and flap activity.

An extract of the simulated time series of the blade root flapwise bending moment, and of the corresponding flap actions is displayed in figure 6; the load series with active flap control have the same mean value as the reference one, but the load variations are decreased and some peaks smoothed out, thus indicating correct operation of the active flap control in all the three configurations. The time series of the flap actions remark how the load variation achieved by the flap actuators is far less than the load variations caused by the disturbances, often pushing the flap actuators to their deflection limits of $\pm 10^{\circ}$. Future work should 
thus investigate the benefit of a control algorithm, e.g. model predictive control, that accounts for the flap deflection constraints, and it should determine whether higher load alleviations could be achieved with a more powerful actuator setup.
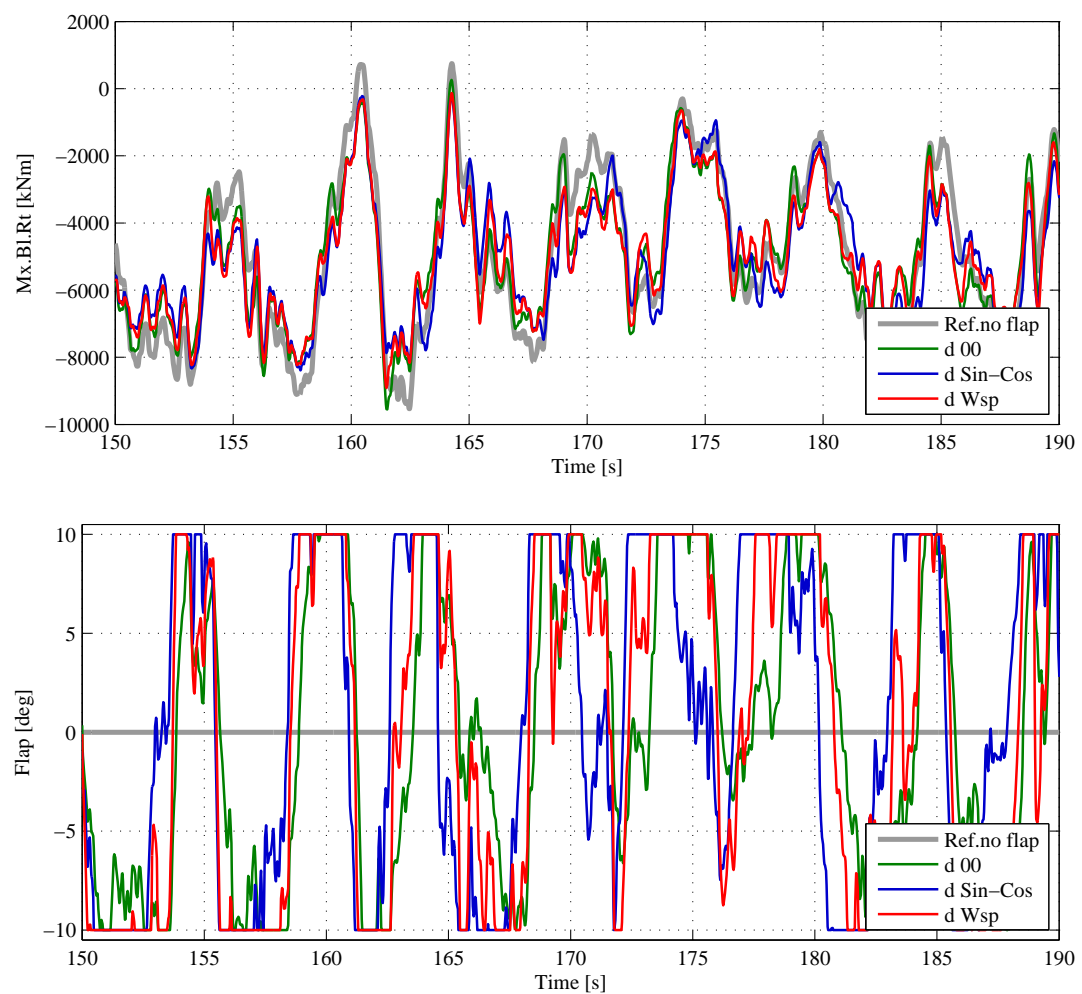

Figure 6: Extract of time series simulation at mean wind speed of $16 \mathrm{~m} / \mathrm{s}$. Blade root flapwise bending moment (top), and flap activity (bottom). The reference case of no active flap control is reported with the light gray line, the active flap configurations with green, blue, and red lines.

The loads on the rotating blade obtained from one hour simulation with mean wind speed $16 \mathrm{~m} / \mathrm{s}$ are plotted versus the blade azimuthal position, figures 7 and 8 . The mean load at each azimuthal position is indicative of the periodic component of the load variation (lines with markers); whereas, the dashed lines displaying the standard deviation range represent the influence of the stochastic load component, which is mainly generated by the atmospheric turbulence. The active flap control reduces both the periodic variations of the flapwise bending moment (fig. 7), and the stochastic component of the loads. The reduction of the stochastic component is similar for the three control configurations, as it mainly depends on the feedback mechanism of the LQ control. On the contrary, the alleviation of the periodic load variation is more marked in the $d$ Sin-Cos and $d W s p$ configurations, which handle periodic disturbance anticipation; the loads from $d W s p$ simulations also displays a slightly smoother variation around the tower passage (notch at $20^{\circ}$ azimuth), although the positive effects of the more accurate periodic disturbance description (cfr fig. 4) are partly limited by the flap actuators reaching their deflection limits.

The reduction of the blade flapwise bending moment comes at the price of 


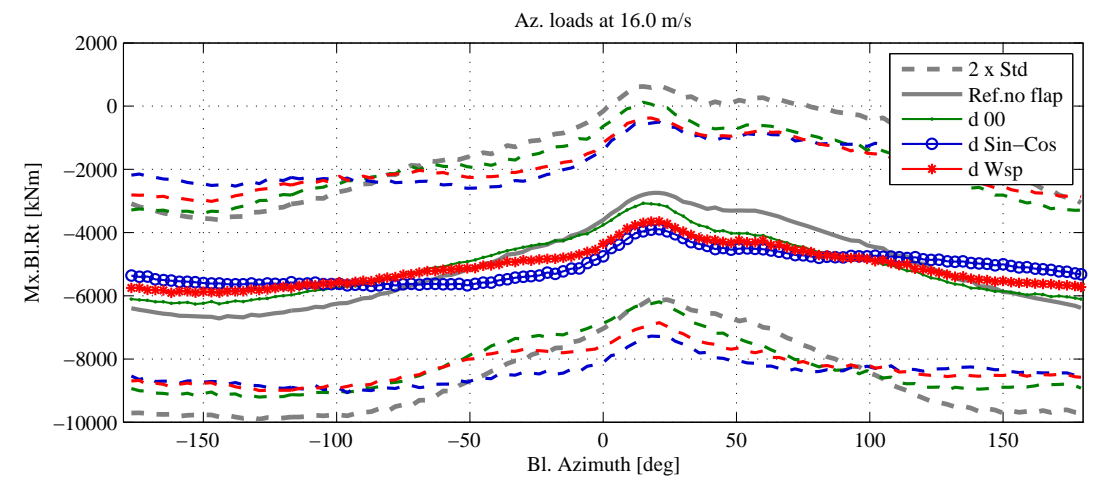

Figure 7: Blade root flapwise bending moment versus blade azimuthal position. Results for $1 \mathrm{hr}$ simulation at mean wind speed of $16 \mathrm{~m} / \mathrm{s}$. For each azimuthal position the means of the simulated loads (lines with markers) indicate the periodic component of the load variation, the standard deviations (dashed lines) are instead proportional to the stochastic load variation. Active flap control reduces both component of the flapwise load variation.

increased variations of the blade torsion moment (fig. 8), which are caused by the aerodynamic pitching moment introduced by the flaps. Usually, the blade torsion loads are not a driving parameter in rotor design, nevertheless the substantial increase that might be generated by active aerodynamic devices should be taken into account in future smart rotor designs. Active flap control slightly increases the range of load variations also on the blade edgewise bending moment, but gravity loads are by far still dominating in this direction.

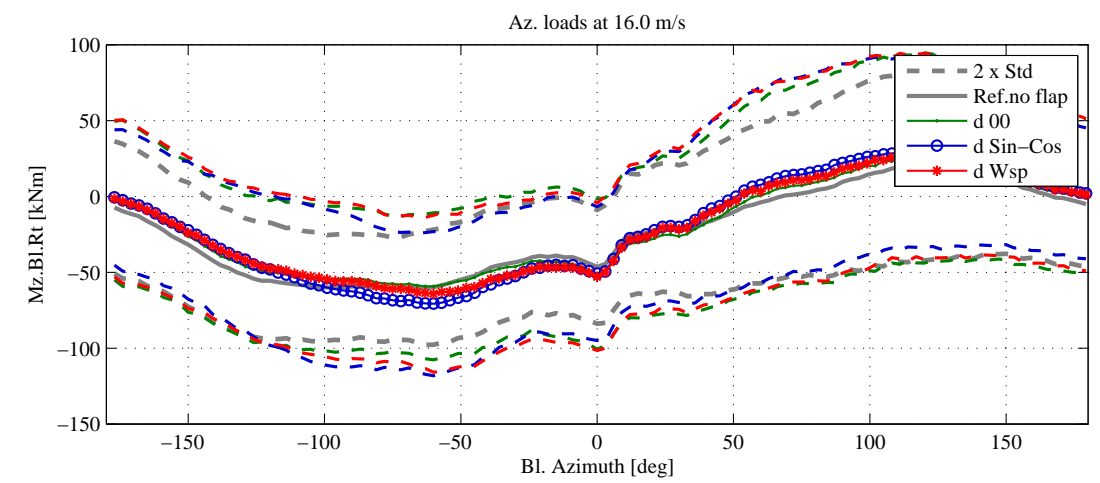

Figure 8: Blade root torsion moment versus blade azimuthal position. Results for $1 \mathrm{hr}$ simulation at mean wind speed of $16 \mathrm{~m} / \mathrm{s}$. As before, the plot displays the periodic component of the loads (mean), and the stochastic one (standard deviation). Active flap control produces an increase in the torsion load variations.

The effects of the active load control are verified for the whole range of mean wind speeds above rated conditions, from 12 to $24 \mathrm{~m} / \mathrm{s}$. For each mean wind speed and each control configuration simulations are carried out for a total of one hour turbulent wind (divided into six ten minutes turbulence seeds), as prescribed by the normal turbulence model in the IEC standard [30]. Statistics on the simulated loads confirm the observations of the azimuthal load analysis: the mean flapwise bending moment is unchanged (fig. 9), whereas the maximum 
load variations (distance between the upper and lower dashed lines) are reduced by approximately $13 \%$. The standard deviation of the flapwise load displays significant variations among the turbulence seeds, but still shows a marked reduction in the cases with active flap control; on average, the standard deviation with the $d 00$ active control configuration is $15.5 \%$ lower than in the not controlled case, and higher reduction are achieved with the $d$ Sin-Cos configuration $(22 \%)$ and the $d W s p$ one $(24 \%)$. As already observed, active flap control has also an effect on other loads on the structure: the standard deviation of the blade torsion moment is increased, whereas a reduction of the load variation is observed at the tower bottom flange, where the standard deviation in the foreaft bending moment is $7 \%$ lower than in the reference case. Minor reductions in standard deviation are also observed on the shaft yaw and tilting moments, and on the tower top yaw moment.
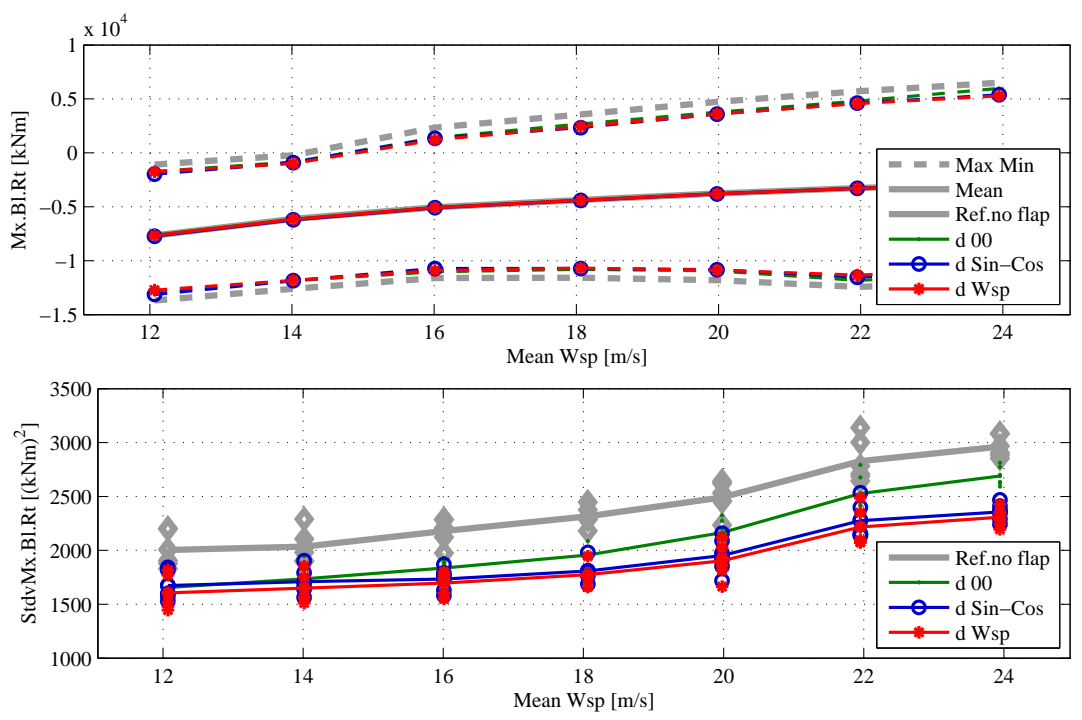

Figure 9: Load statistics: blade root flapwise bending moment mean and load ranges (top), and loads standard deviation (bottom). Each of the mark in the standard deviation plot corresponds to a single 10 minutes time simulation. Active flap control reduces the load range, and the standard deviation.

The total activity required by the active load control to the flap actuators is measured as the total angular distance traveled by the flap, either with upward or downward deflections; the angular distance is then normalized by the total operation time, thus returning an average deflection speed, figure 10. The $d W s p$ control configuration, which achieves higher reductions of the flapwise loads standard deviation, also demands higher flap activity; the $d 00$ configuration, instead, in spite of lower alleviation performances, requires higher flap activity than the $d$ Sin-Cos configuration. The reduction of flap activity as the mean wind speed increases, in spite of increased loads variations, is probably explained by the flap reaching more often the actuator deflection limits. The maximum deflection rate of the flap actuator is not constrained in the simulations. Nevertheless, with the frequency weighting penalizing high frequency flap activity, $99 \%$ of the flap activity observed in the simulations requires deflection rates below $90 \mathrm{deg} / \mathrm{s}$; the introduction of deflection rate constraints close 
or above this limit is thus expected to have no significant effects on the smart rotor load alleviation potential.

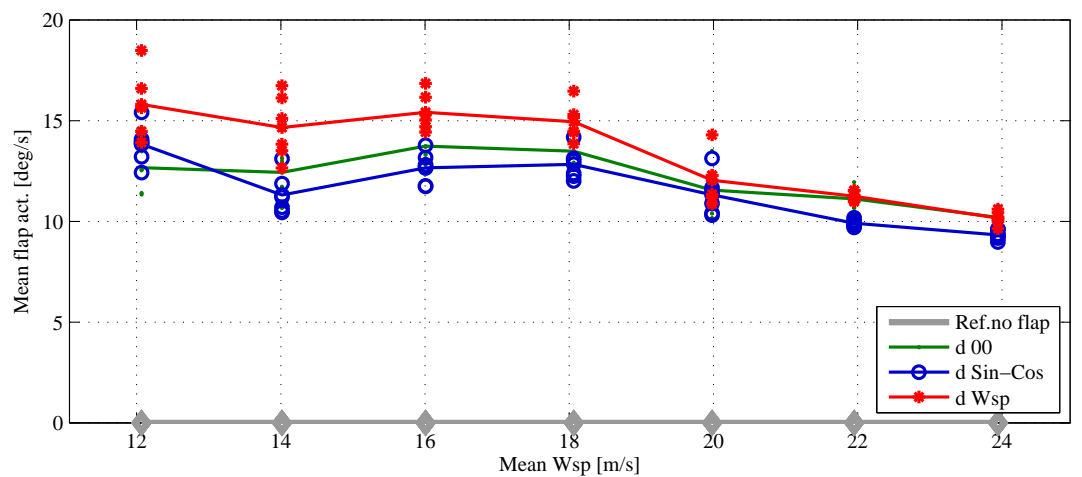

Figure 10: Flap activity for the three control configurations. Total flap traveled distance normalized by the simulation time, for each of the investigated mean wind speeds.

The power spectral density of the blade flapwise moment, figure 11, shows that most of the load alleviation occur for frequencies close to $1 \mathrm{P}$, the rotor revolution frequency $(0.2 \mathrm{~Hz})$. A small increase in the spectral energy content is instead observed around $1 \mathrm{~Hz}$. The increase is limited by the frequency weighting, but the introduced penalization appear not sufficient to keep the power spectrum below the baseline value in this frequency range; attempts to further increase the frequency penalization resulted in lower flap activity, but also lower blade load alleviation. The power spectrum of the flap activity (fig. 12 ) is dominated by the $1 \mathrm{P}$ rotational frequency and its harmonics; the frequency content of the flap activity decreases significantly above $1 \mathrm{~Hz}$, both as an effect of the frequency weighting, and also for the lower energy content in the loads addressed by the flap control.

The performance of the smart rotor is finally quantified in terms of reduction of fatigue damage equivalent loads (DEL). The equivalent loads are computed under Palmgren-Miner linear damage assumption [38], and a Wöhler curve exponent of 10 is used for the loads on the blades, and 4 for the rest of the structure. The damage equivalent loads are here referred to 25 years of operation, and 10 millions equivalent cycles; the mean wind speed occurrence is weighted according to a Rayleigh distribution with $8.5 \mathrm{~m} / \mathrm{s}$ average wind speed, as prescribed by the IEC standard [30] for a class II turbine.

The active flap control succeeds in all the investigated configurations in reducing the fatigue damage of the blade root flapwise bending moment, figure 13. The $d 00$ configuration, acting exclusively on the feedback from bending moment measurements, has the poorest performance, with alleviations ranging from 7.5 to $12.6 \%$ at low wind speed, and a total lifetime fatigue equivalent damage load by $10.2 \%$ lower than the reference case without active flap control. The control configurations with periodic disturbances anticipation achieve higher reductions: the $d$ Sin-Cos control alleviates the lifetime fatigue damage by $13.8 \%$, and the $d W s p$ configuration reaches a lifetime reduction of $14.5 \%$, albeit with higher flap activity. Looking at each of the 10 minutes turbulence series individually, markers in figure 13, a large spread in the load alleviation potential is reported among the different simulation series, ranging from $9 \%$ to 


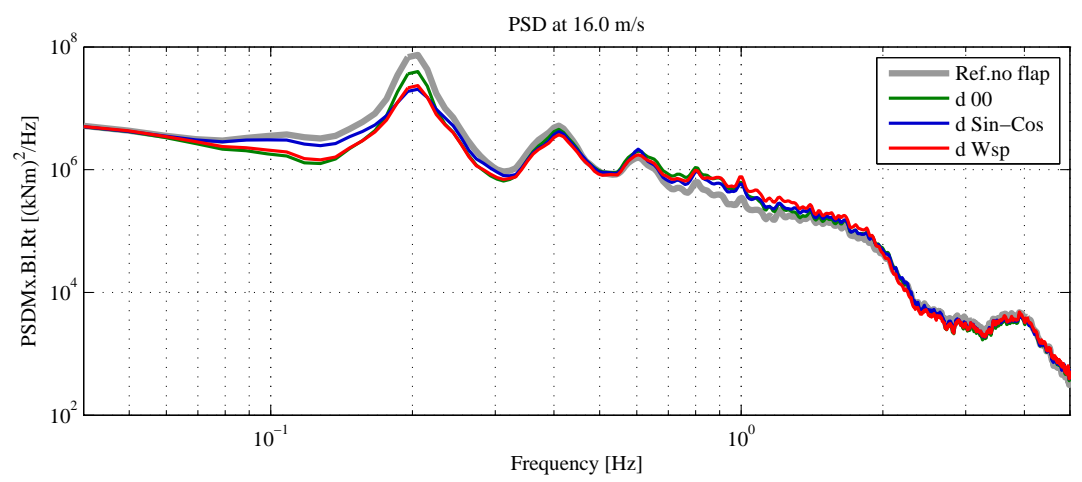

Figure 11: Power spectral density of the blade root flapwise bending moment; the plot refers to simulations with mean wind speed of $16 \mathrm{~m} / \mathrm{s}$, similar figures are obtained for the other investigated wind speed. The load reduction from the active flap control is mainly concentrated in the frequency range around $1 P$, the rotor revolution frequency of $0.2 \mathrm{~Hz}$.

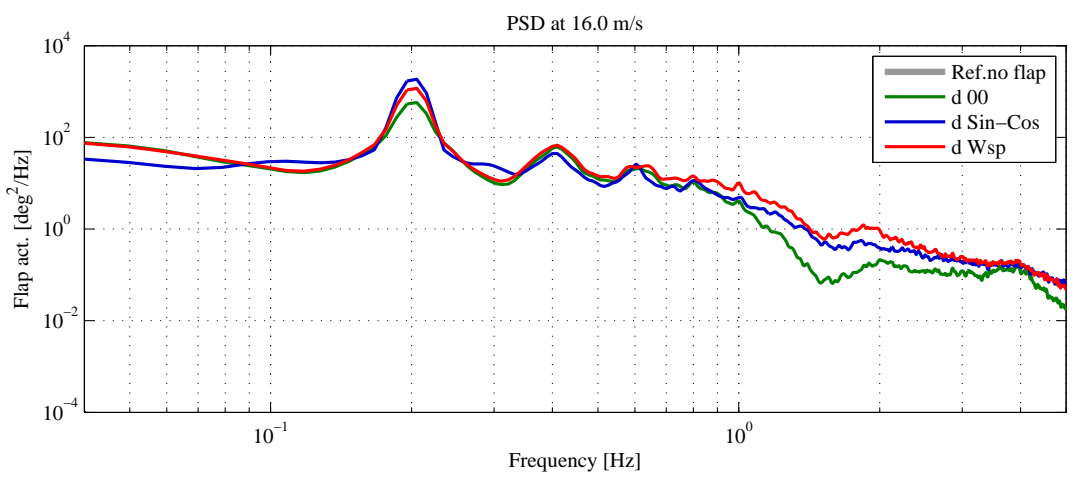

Figure 12: Power spectral density of the flap activity. For the three control configurations most of the flap activity is concentrated around the rotational frequency $1 \mathrm{P}(0.2 \mathrm{~Hz})$ and its harmonics.

$19 \%$. Experiment or simulation in turbulent wind conditions should thus consider time series of sufficient length to ensure statistically relevant conclusions on the load alleviation potential; in the investigated case, at least 40 minutes of simulation are required to reach alleviation estimations within one point percent of the result obtained by turbulent wind simulation of 60 minutes, which is the minimum requirement specified by the IEC standard [30].

The active flap control also affects the fatigue damage of components not included in the control objectives. The lifetime damage equivalent load on the blade root torsion moment is increased by about $10 \%$; the blade edgewise bending moment and the shaft torsion DEL are also increased by about $6 \%$. On the other hand, a reduction in the fatigue damage is observed at the tower bottom flange, in the fore-aft direction, figure 14: the $d 00$ configuration reduces the tower lifetime damage by $6.5 \%$, and smaller figures are obtained with $d W s p$ $(5.6 \%)$, and $d$ Sin-Cos (3\%). In spite of a reduction in the standard deviation, the tower side-to-side loads and the bending moment on the shaft do not report relevant changes in the lifetime fatigue damages.

To verify the performance of the active flap control in operation conditions 


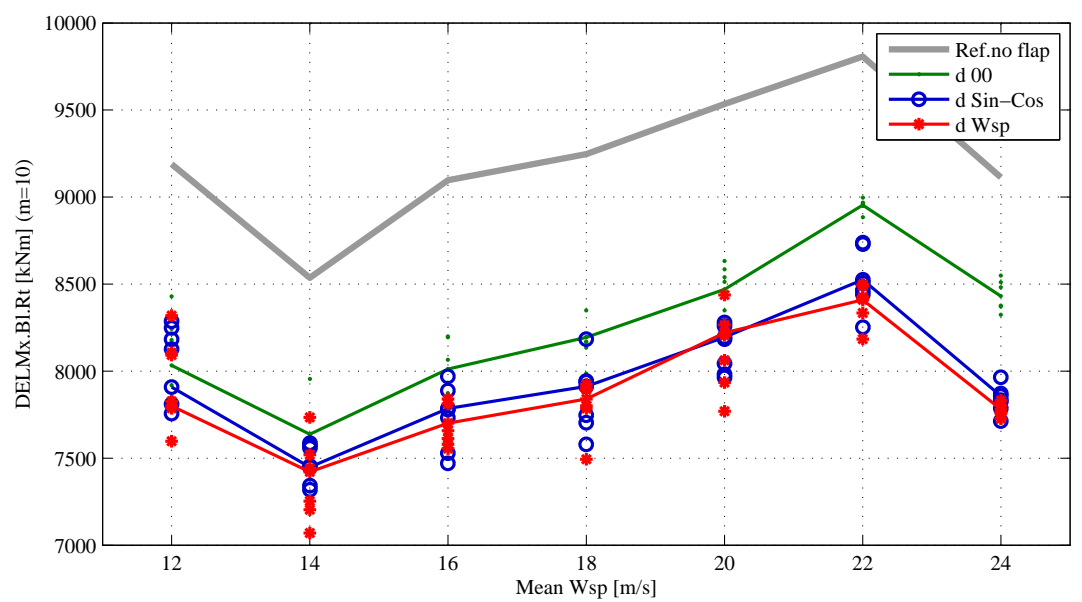

Figure 13: Fatigue Damage Equivalent Loads (DEL) at the blade root flapwise bending moment. The DEL refer to a 25 yr lifetime and 10 millions equivalent cycles, the figures at each mean wind speed are weighted by the occurrence of the mean wind speed according to a Rayleigh distribution for a class II turbine. The dots report the spreading of fatigue damage reduction recorded in each of the 10 minutes simulation series.

slightly different from the control design ones, a series of simulation is performed with a yaw misalignment error. The blade flapwise damage equivalent loads are computed for one hour simulation with mean wind speed of $16 \mathrm{~m} / \mathrm{s}$ and yaw misalignment of $\pm 8^{\circ}$, figure 15 ; the same flap control configurations as in the normal production cases are used, without any re-tuning nor modifications of the periodic disturbance signals. The fatigue damage equivalent load is higher than in the aligned case for positive yaw misalignment, i.e. the right hand side part of the rotor (looking downwind) is displaced to leeward; the fatigue reduction from the active flap control is also slightly higher than in the alligned rotor case: $12.2 \%$ for $d 00,15.5 \%$ for $d$ Sin-Cos, and $15.7 \%$ for $d W s p$. On the contrary, for the negative yaw misalignment, the fatigue damage is slightly lower, and so is the reduction from the active flap control, with figures ranging from $11.2 \%$ to $14.2 \%$, figure 15 . As in the aligned case, the flap control reduces the loads at the tower bottom flange in the fore-aft direction, while it increases the blade torsion and edgewise bending fatigue damages. The tower and shaft yaw fatigue damage loads, in both cases higher than in the aligned case, are nearly left unchanged by the active flap control, but the maximum loads are instead reduced by approximately $14 \%$ when the flap load control is active.

\section{Conclusion}

Simulations of a smart rotor with adaptive trailing edge flaps are carried out with the aeroelastic code HAWC2, which features an aerodynamic model describing both attached and stalled flow dynamics, and a multibody structural model that accounts also for the blade torsion degree of freedom. Blade torsion is particularly relevant for aeroelastic simulations of a rotor with flaps, as the flap deflection introduces a significant aerodynamic pitching moment; therefore, by omitting the blade torsion compliance, the flap ability to alleviate the loads 


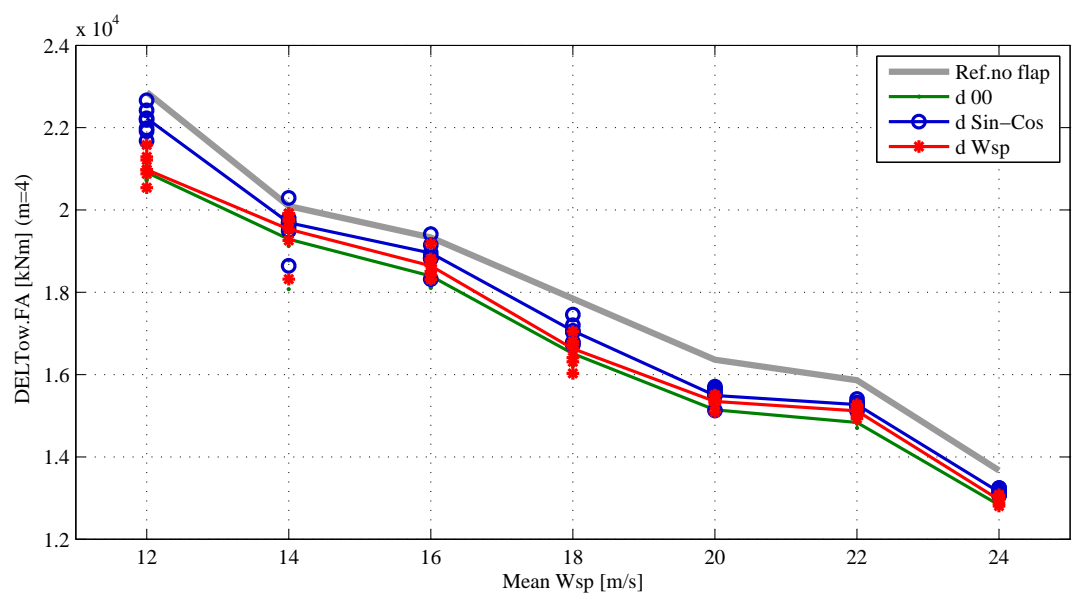

Figure 14: Fatigue Damage Equivalent Loads (DEL) at the tower bottom flange in fore-aft direction. The DEL at each mean wind speed account for the time each mean speed is expected to occur (higher wind speeds are less likely, hence they yield lower fatigue damage).

on the blade would be overestimated. The adaptive trailing edge flaps are applied to the NREL 5 MW reference turbine rotor [36]; they cover $20 \%$ of the blade span, and are controlled by a linear quadratic (LQ) algorithm based on a simple sensor arrangement: the flap on each of the blades is controlled based on the root flapwise bending moment and azimuthal position of the same blade. The effects of the active flap control are quantified in terms of load statistics, spectra, and fatigue damage equivalent loads, reproducing the simulation conditions prescribed by the IEC standard [30] for a class IIb turbine.

Active flap control allows to reduce the maximum load range on the blade root flapwise bending moment by approximately $13 \%$, and the standard deviation of the bending moment is 15-24\% lower than in the reference case without active control. The adaptive flap controllers alleviate loads mainly in the low frequency range of the spectrum $(0.1-0.5 \mathrm{~Hz})$, and especially around the $1 \mathrm{P}$ rotational frequency $(0.2 \mathrm{~Hz})$. As the loads in the low frequency range are responsible for the largest contribution to the blade root flapwise fatigue damage $[19,27]$, it is beneficial to discourage the activity of the flap actuators at higher frequencies by introducing a frequency-dependent weighting in the LQ control algorithm. The frequency weighting penalizes control activity at frequencies above $0.5 \mathrm{~Hz}$, thus limiting the total flap movement and the maximum deflection rate, hence effectively reducing the wear of hypothetical flap actuators.

Ultimately, the effects of the adaptive trailing edge flap control are quantified in terms of lifetime fatigue damage equivalent load reduction. The control configuration based on only measurements feedback ( $d 00)$ lowers the lifetime fatigue equivalent damage on the blade root flapwise bending moment by about $10 \%$, a result in line with previous investigations that considered similar setups $[12,17]$. Periodic load anticipation, which is based on the blade azimuthal position and handled by the LQ algorithm as a prediction on periodic disturbance signals, allows to reach higher lifetime damage alleviation: $13.8 \%$ with the $d$ Sin-Cos configuration, and $14.5 \%$ with $d W s p$. The increase in load alleviation potential by nearly $4 \%$ achieved by including periodic load antici- 


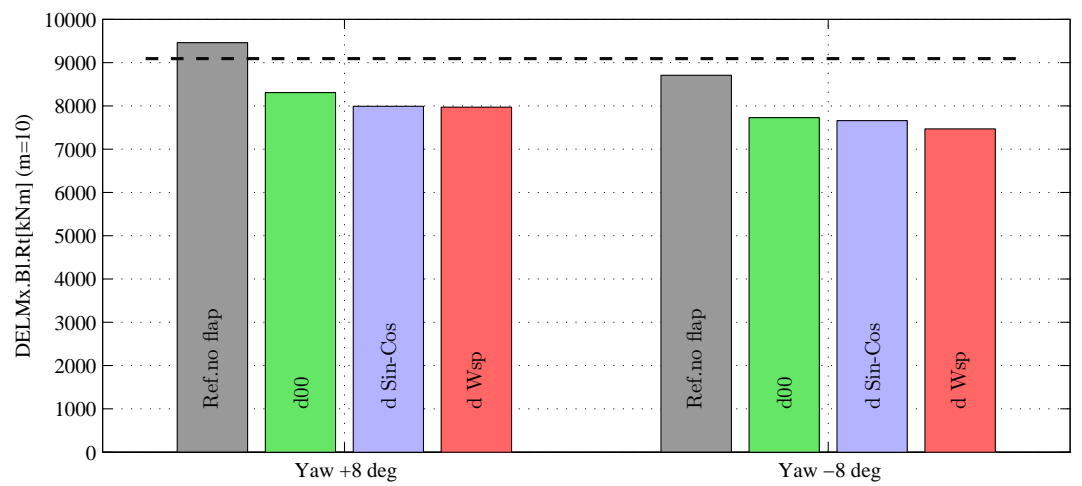

Figure 15: Fatigue Damage Equivalent Loads (DEL) at the blade root flapwise bending moment for the rotor in yawed conditions for operation at a single mean wind speed (16 $\mathrm{m} / \mathrm{s})$; positive yaw angles imply that the right hand side of the rotor (looking downwind) is displaced to leeward. The dashed black line correspond to the DEL reported for the aligned rotor in the reference case of no flap control.

pation is comparable to the increase previous investigations have attained using additional in-flow sensors $[12,14]$, with the advantage that the periodic load anticipation approach does not require a sensor setup as complicate and delicate as demanded for in-flow measurements. As an effect of active load alleviation with adaptive trailing edge flaps, a significant increase of the blade torsion fatigue damage equivalent load is reported (nearly $10 \%$ ); the increase of the torsional loads, and, to a lesser extent, of loads on other components, should be hence taken into account in the design of smart rotor structures. Positive reduction of damage equivalent loads are instead reported for the tower bottom flange fore-aft bending moment (by approx. 5\%); the load alleviation on the blade flapwise moment and on the tower bottom flange are also confirmed in yawed inflow conditions.

To conclude with a consideration on possible future work, according to the results reported in this study and in the literature, the load alleviation potential achieved by the smart rotor appears to be mainly limited by the strength of the aerodynamic actuators employed on the rotor. In fact, the variation of blade root flapwise bending moment obtained by the current flap setup is simply too small to compensate to an higher degree for the load variations observed on the blade during normal operation. Future work should thus consider, first, whether a control algorithm that handles flap deflection constraints, as for instance model predictive control [21, 12], could improve the load alleviation performances. Secondly, future investigations might focus on whether fatigue loads could be further reduced by fitting the smart rotor with a more powerful actuator setup, either by augmenting the blades surface covered by adaptive flaps, or by complementing the flap efforts with individual blade pitch actions.

\section{Acknowledgment}

It is gratefully acknowledged that this work is partly funded by the Danish project Development of Adaptive Trailing Edge Flap (ATEF) System for Wind Turbines by the Advanced Technology Foundation, Advanced Technol- 
ogy Projects 2007.

\section{References}

[1] Barlas TK, van Kuik G. State of the art and prospectives of smart rotor control for wind turbines. Journal of Physics: Conference Series 2007; 75(1):012080 (20 pp.).

[2] Bossanyi EA. Individual blade pitch control for load reduction. Wind Energy $2003 ; \mathbf{6}(2): 119-128$.

[3] Larsen TJ, Madsen HA, Thomsen K. Active load reduction using individual pitch, based on local blade flow measurements. Wind Energy 2005; 8(1):6780 .

[4] Troldborg N. Computational study of the Riso-B1-18 airfoil with a hinged flap providing variable trailing edge geometry. Wind Engineering 2005; 29(2):89-113.

[5] Buhl T, Gaunaa M, Bak C. Potential load reduction using airfoils with variable trailing edge geometry. Transactions of the ASME.Journal of Solar Energy Engineering 2005; 127(4):503-516.

[6] Johnson SJ, Baker JP, van Dam CP, Berg D. An overview of active load control techniques for wind turbines with an emphasis on microtabs. Wind Energy Mar 2010; 13(2-3):239-253, doi:10.1002/we.356.

[7] van Wingerden JW, Hulskamp AW, Barlas T, Marrant B, van Kuik GAM, Molenaar DP, Verhaegen M. On the proof of concept of a 'Smart' wind turbine rotor blade for load alleviation. Wind Energy 2008; 11(3):265-280.

[8] Bak C, Gaunaa M, Andersen PB, Buhl T, Hansen P, Clemmensen K. Wind tunnel test on airfoil risø-b1-18 with an active trailing edge flap. Wind Energy 2010; 13(2-3):207-219, doi:10.1002/we.369.

[9] van Wingerden J, Hulskamp A, Barlas T, Houtzager I, Bersee H, van Kuik G, Verhaegen M. Smart dynamic rotor control: Part 3, advanced controller design. Proc. of the 3rd conference, The Science of Making Torque from Wind, Eraklion, Crete, Greece, 2010; 702-708.

[10] Barlas T, van Wingerden W, Hulskamp A, van Kuik GM, Bersee HN. Smart dynamic rotor control using active flaps on a small-scale wind turbine: aeroelastic modeling and comparison with wind tunnel measurements. Wind Energy 2012; Early View(published on-line), doi:10.1002/we.1560.

[11] Castaignet D, Wedel-Heinen JJ, Kim T, Buhl T, Poulsen N. Results from the first full scale wind turbine equipped with trailing edge flaps. Proceedings of 28th AIAA Applied Aerodynamics Conference, American Institute of Aeronautics and Astronautics: Chicago, IL (US), 2010, doi: $10.2514 / 6.2010-4407$.

[12] Barlas TK, van der Veen GJ, van Kuik GA. Model predictive control for wind turbines with distributed active flaps: incorporating inflow signals and actuator constraints. Wind Energy 2011; doi:10.1002/we.503. 
[13] Riziotis VA, Voutsinas SG. Aeroelastic modeling of the active flap concept for load control. Scientific proceedings. 2008 European Wind Energy Conference and Exhibition, Brussels (BE), 2008; 22-26.

[14] Andersen PB, Henriksen LC, Gaunaa M, Bak C, Buhl T. Integrating deformable trailing edge geometry in modern mega-watt wind turbine controllers. Scientific proceedings. 2008 European Wind Energy Conference and Exhibition, Brussels (BE), 2008; 15-21.

[15] Resor B, Wilson D, Berg D, Berg J, Barlas T, van Wingerden JW, van Kuik GAM. Impact of higher fidelity models on simulation of active aerodynamic load control for fatigue damage reduction. Proceedings of the 48 th AIAA/ASME, Orlando, FL, 2010.

[16] Andersen PB, Henriksen L, Gaunaa M, Bak C, Buhl T. Deformable trailing edge flaps for modern megawatt wind turbine controllers using strain gauge sensors. Wind Energy Mar 2010; 13(2-3):193-206, doi:10.1002/we.371.

[17] Baek P. Unsteady flow modeling and experimental verification of active flow control concepts for wind turbine blades. Ph.D. thesis, Risoe DTU, Technical University of Denmark, Roskilde, Denmark Dec 2011.

[18] Barlas TK, Van Kuik GAM. Aeroelastic modelling and comparison of advanced active flap control concepts for load reduction on the upwind 5MW wind turbine. European Wind Energy Conference, Marseille, France, 2009; $16-19$.

[19] Lackner MA, van Kuik G. A comparison of smart rotor control approaches using trailing edge flaps and individual pitch control. Wind Energy Mar 2010; 13(2-3):117-134, doi:10.1002/we.353.

[20] Wilson D, Resor B, Berg D, Barlas T, van Kuik G. Active aerodynamic blade distributed flap control design procedure for load reduction on the UpWind 5MW wind turbine. Proceedings of the 48th AIAA Aerospace Sciences Meeting, 2010; 4-7.

[21] Castaignet D, Poulsen NK, Buhl T, Wedel-Heinen JJ. Model predictive control of trailing edge flaps on a wind turbine blade. Proceedings of the American Control Conference 2011, San Francisco, CA, USA, 2011.

[22] Berg D, Wilson D, Resor B, Berg J, Barlas T, Crowther A, Halse C, House R. System ID modern control algorithms for active aerodynamic load control and impact on gearbox loading. Proceedings of the Conference on the Science of Making Torque from Wind, 2010.

[23] Åstrom KJ. Introduction to stochastic control theory, Mathematics in science and engineering, vol. 70. Academic Press: London, 1970.

[24] Ljung L. System identification: theory for the user. PTR Prentice-Hall: Upper Saddle River (NJ), 1999.

[25] Lewis FL, Vrabie D, Syrmos VL. Optimal control. Wiley, 2012. 
[26] Houtzager I, van Wingerden JW, Verhaegen M. Wind turbine load reduction by rejecting the periodic load disturbances. Wind Energy May 2012; doi:10.1002/we.547.

[27] Bergami L, Gaunaa M. Analysis of aeroelastic loads and their contributions to fatigue damage. Submitted to Journal of Physics: Conference Series Oct 2012 ;

[28] Larsen TJ. How 2 HAWC2 the user's manual. Technical Report $R$ 1597(EN), Ris $\varnothing$ National Laboratory. Technical University of Denmark 2009.

[29] Bergami L, Riziotis VA, Gaunaa M. Aerodynamic response of an airfoil section undergoing pitch motion and trailing edge flap deflection: a comparison of simulation methods. Wind Energy May 2014; Early-vew(published on-line), doi:10.1002/we.1759.

[30] International Electrotechnical Commission. IEC 61400-1: Wind turbines part 1: Design requirements. Technical Report, International Electrotechnical Commission 2005.

[31] Mann J. Wind field simulation. Probabilistic Engineering Mechanics Oct 1998; 13(4):269-282, doi:10.1016/S0266-8920(97)00036-2.

[32] Madsen HA, Riziotis V, Zahle F, Hansen MO, Snel H, Grasso F, Larsen TJ, Politis E, Rasmussen F. Blade element momentum modeling of inflow with shear in comparison with advanced model results. Wind Energy May 2012; 15(1), doi:10.1002/we.493.

[33] Gaunaa M. Unsteady two-dimensional potential-flow model for thin variable geometry airfoils. Wind Energy 2010; 13(2-3):167-192, doi:10.1002/ we.377.

[34] Hansen MH, Gaunaa M, Madsen HA. A beddoes-leishman type dynamic stall model in state-space and indicial formulations. Technical Report $R$ 1354(EN), Risoe National Laboratory, Roskilde (DK) 2004.

[35] Bergami L, Gaunaa M, Heinz J. Indicial lift response function: an empirical relation for finite-thickness airfoils, and effects on aeroelastic simulations. Wind Energy 2013; 16(5):681-693, doi:10.1002/we.1516.

[36] Jonkman J, Butterfield S, Musial W, Scott G. Definition of a 5-MW reference wind turbine for offshore system development. Technical Report NREL/TP-500-38060, National Renewable Energy Laboratory (NREL) Feb 2009.

[37] van der Veen G, van Wingerden J, Verhaegen M. Closed-loop system identification of wind turbines in the presence of periodic effects. Proc. of the 3rd conference, The Science of Making Torque from Wind, Eraklion, Crete, Greece, 2010.

[38] Hansen M. Aerodynamics of wind turbines : rotors, loads and structure. James \& James: London, 2000. 